\section{(6) OPEN ACCESS}

\title{
Virus-associated apoptosis of blood neutrophils as a risk factor for invasive meningococcal disease
}

\author{
Harry Smith, ${ }^{1}$ Sharon L Rogers, ${ }^{2}$ Helen V Smith, ${ }^{3}$ David Gillis, ${ }^{4}$ Victor Siskind, ${ }^{5}$ \\ Judith A Smith ${ }^{1}$
}

Department of Paediatrics, University of Queensland, Royal Children's Hospital, Brisbane,

Queensland, Australia

${ }^{2}$ Division of Haematology,

Pathology Queensland,

Royal Brisbane and Women's

Hospital, Brisbane,

Queensland, Australia

${ }^{3}$ Public Health Microbiology,

Communicable Disease,

Forensic and Scientific Services,

Queensland Health, Brisbane,

Queensland, Australia

${ }^{4}$ Division of Immunology,

Pathology Queensland,

Royal Brisbane and Women's

Hospital, Brisbane,

Queensland, Australia

${ }^{5}$ Cancer Epidemiology Unit,

Queensland Institute of

Medical Research, Brisbane,

Queensland, Australia

\section{Correspondence to}

Dr Harry Smith, Department of

Paediatrics, University of

Queensland, Royal Children's

Hospital, Herston Road,

Brisbane, Queensland 4029,

Australia;

harry.smith@uq.edu.au

Received 4 March 2013

Revised 8 May 2013

Accepted 24 May 2013

Published Online First

25 June 2013

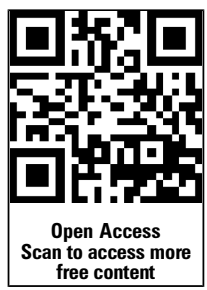

To cite: Smith H, Rogers $\mathrm{SL}$, Smith HV, et al. J Clin Pathol 2013;66:976-981.

\section{ABSTRACT}

Aims To quantify a range of haematological indicators of viral infection (leucocyte apoptosis, cytopenia of normal lymphocytes, reactive lymphocyte increase, neutropenia) in patients with recent onset invasive meningococcal disease (IMD), with a view to test the association of viral infection with IMD and identify possible haematological risk factors for its development. Subjects and methods 88 patients with recent onset IMD, classified on clinical severity as fatal $(n=14)$, septic shock survived $(n=26)$ and no shock $(n=48)$, and 50 healthy controls were studied. Blood film microscopy and leucocyte counts were used to quantify the virusassociated indicators. Cocci-containing neutrophils were also quantified.

Results All viral parameters were significantly more frequent or higher in patients than controls, with leucocyte apoptosis found only in the patients.

A significant gradient in accord with clinical severity was found for neutrophil and lymphocyte apoptosis, neutropenia and cocci-containing neutrophils. Crucially, apoptotic neutrophils did not contain cocci, and coccicontaining neutrophils were not apoptotic.

Conclusions The correlation between magnitude of neutrophil apoptosis and severity of IMD suggests a cause-effect relationship. We propose that neutrophil apoptosis is more likely a facilitator rather than an effect of IMD for these reasons: (1) apoptotic neutrophils did not contain cocci and cocci-containing neutrophils were not apoptotic, (2) leucocyte apoptosis is a recognised viral effect and (3) Neisseria meningitidis is incapable of producing a Panton-Valentine type leucocidin. The lymphocyte apoptosis which accompanies neutrophil death may contribute to risk by impairing the generation of microbicidal antibody. Leucocyte apoptosis is a morphological expression of viral immunosuppression and, we suggest, is a likely contributor to a range of viral effects.

\section{INTRODUCTION}

A variety of factors affecting nasopharyngeal mucosal integrity, systemic immunity and the biology of the organism itself are risk factors for recent onset invasive meningococcal disease (IMD). These include: preceding viral infection, especially influenza $\mathrm{A},{ }^{1}$ mycoplasma infection, ${ }^{2}$ cigarette smoking, exposure to cigarette smoke or smokers, exposure to construction site dust, ${ }^{3-5}$ and deficiencies in systemic immunity relating to serum bactericidal antibody to meningococcus, ${ }^{6}{ }^{7}$ mannose-binding lectin ${ }^{8} 9$ and more rarely, deficiencies in components of the terminal pathway of complement activation or properdin. ${ }^{10} \mathrm{~A}$ single risk factor may operate through several mechanisms; for example, the fact that postinfluenzal spikes of IMD are in general not accompanied by increased meningococcus carriage has suggested virus-induced neutrophil dysfunction as a contributor to risk. ${ }^{1}$ In addition, viruses have the capacity to enhance mucosal adhesiveness for bacteria ${ }^{11} 12$ or, in the case of influenza A, the capacity of its neuraminidase to cleave the sialic acid-containing capsular polysaccharides of Neisseria meningitidis serogroups B, C and W135 to enhance adhesiveness to epithelial surfaces. ${ }^{13}$ The innate capacity of the bacterial strain for invasiveness through epithelium is also significant in pathogenesis of IMD. ${ }^{14}$

We quantified a range of haematological indicators of viral infection with the aims of substantiating, from a novel perspective, the linkage between viral infection and IMD and of identifying possible haematological risk factors for its development. Leucocyte apoptosis was assessed, in addition to traditional leucocytic indicators of viral infection: ${ }^{15}$ reactive lymphocyte increase, cytopenia of normal lymphocytes (lymphocytopenia) and neutropenia. Apoptosis of leucocytes, including reactive lymphocytes, is a feature of the blood film in viral infections, including infectious mononucleosis (IM) ${ }^{16-19}$ (figures 2 and 3), neonatal herpes simplex viraemia $^{17}{ }^{20}$ (figure 1), rubella, measles ${ }^{17}$ and influenza A infection (Kerwick A-M, unpublished), and is the basis for the macrophage phenomenon in earlobe blood: ${ }^{16} 21$ monocytes/macrophages containing degenerate leucocytes (figure 3, ie, a process of haemophagocytosis), on account of their size, accumulate in the rich capillary bed of the earlobe, with simultaneous venous blood films showing few or none of these cells. The occurrence of apoptotic lymphocytes in the blood film in IM correlates with the upregulation of the Fas-receptor/Fas-ligand (Fas-L) system on the primed T lymphocyte population, ${ }^{22}$ and its propensity to substantial death in culture. ${ }^{23-25}$

\section{SUBJECTS AND METHODS}

\section{Patients and controls}

A total of 88 patients with recent onset IMD notified to the Queensland Health Public Health Microbial Reference Laboratory between October 2003 and October 2005 were studied. In all cases, cultures were positive from blood and/or cerebrospinal fluid, except for one patient, with culture positive only from the anterior chamber of an affected eye (table 1). Patients were classified into three groups on clinical severity: fatal, septic shock survived (hypotension with or without poor capillary refill) and no shock. There was a trend, but not significant, toward over-representation of 
Figure 1 Apoptotic neutrophil (left), apoptotic lymphocyte (right), blood film, neonatal herpes simplex viraemia. Reproduced, with permission, from Smith H. Diagnosis in Paediatric Haematology 1996.

Churchill-Livingstone ${ }^{\circ}$, Elsevier.
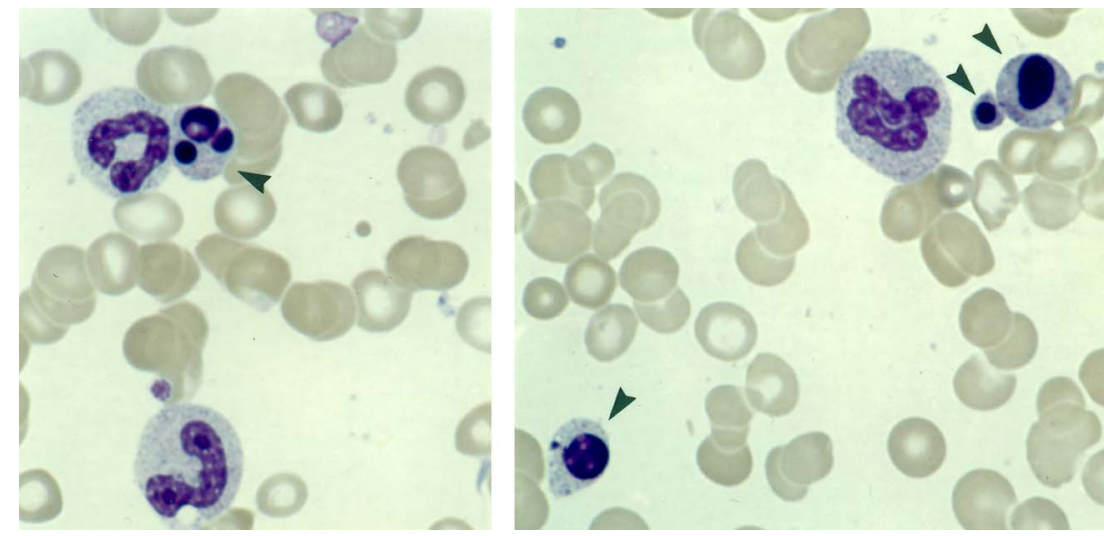

younger patients in the fatal group. There was a significant overrepresentation of serogroup $\mathrm{C}$ in the fatal group. The control group comprised asymptomatic individuals with no clinical history of infection for at least 3 weeks prior to test. Children in this group were elective admissions for clean surgical procedures such as hernia repair.

\section{Blood film microscopy}

Wright's stained blood films prepared immediately on receipt of EDTA-anticoagulated venous blood were used. Films were examined with an oil immersion $\times 60$ planapochromat objective in the optimal part (one cell thick, evenly spread), working methodically in zigzag fashion from one edge to the other to end with a total of about 400-1000 leucocytes examined, depending on the leucocyte count (which took about $5 \mathrm{~min}$ ). Large granular lymphocytes were counted as normal lymphocytes.

Apoptosis (figures 1-3) was identified by condensation, obliteration of fine structure and glassy homogenisation of nuclear chromatin, leaching of chromatin stain into the cytoplasm, nuclear pyknosis and disintegration, and shrinkage of nucleus and cell as a whole. In advanced degeneration, especially of neutrophils, the chromatin may lose colouration and stain grey (figure 3). Some degenerate lymphocytes were recognisable as reactive or large granular types. These changes were readily distinguishable from anticoagulant/storage artefact. ${ }^{26}$

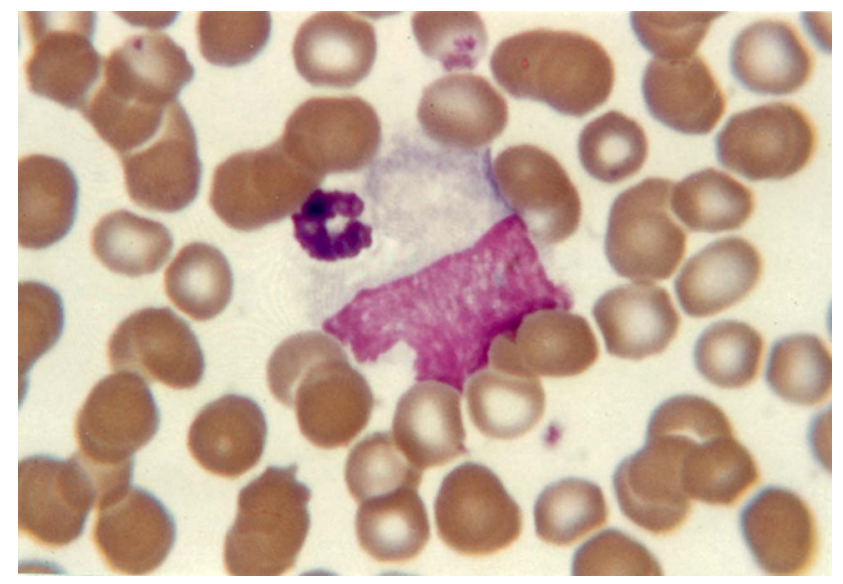

Figure 2 Degenerate neutrophil adherent to monocyte, earlobe blood film, infectious mononucleosis. Reproduced, with permission, from Smith H. Diagnosis in Paediatric Haematology 1996.

Churchill-Livingstone @ , Elsevier.
Established age-appropriate normal ranges for leucocyte counts $^{15} 17$ were applied. Age-appropriate upper limits of normal for reactive lymphocytes were taken from our data for the controls as: for those $<5$ years, $<0.09 \times 10^{9} / \mathrm{L}$ $\left(<90\right.$ per $\left.\mathrm{mm}^{3}\right)$ and for those $\geq 5$ years, $<0.06 \times 10^{9} / \mathrm{L}$ $\left(<60\right.$ per $\left.\mathrm{mm}^{3}\right)$. Apoptotic leucocytes and cocci-containing neutrophils (figure 4) were quantified both as a count per $\mathrm{mm}^{3}$ and, less precisely though nevertheless of some practical utility, as the proportion of subjects positive for the feature. This latter mode of expression of results, being only semiquantitative, was not subjected to statistical analysis. Cocci-containing monocytes ${ }^{17}$ were not seen in this study.

\section{Statistics}

Proportions were compared by contingency tables analysis, including Armitage-Mantel-Haenzel ordered test between patient groups. Quantitative variables were compared by Kruskal-Wallis non-parametric one-way analysis ( $\chi^{2}$ statistics).

\section{RESULTS}

All viral parameters were significantly greater or more frequent in patients than in controls, with leucocyte apoptosis found only in the patients (table 2). The following characteristics showed a significant gradient in accord with clinical severity: apoptotic leucocytes as a whole (which included on average across all patient groups, $14.4 \%$ of dead leucocytes of unidentified type), apoptotic neutrophils, apoptotic lymphocytes,

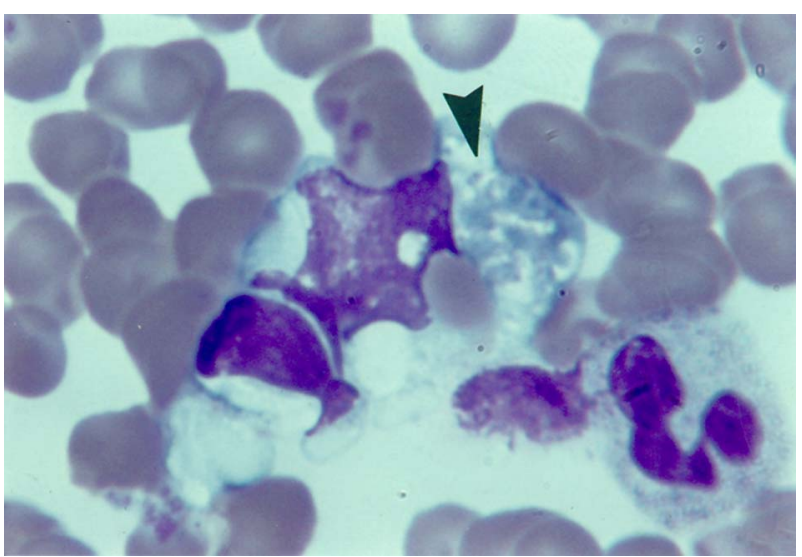

Figure 3 Inclusions of lymphocyte, erythrocyte and neutrophil in advanced degeneration (arrow) in monocyte, earlobe blood film, infectious mononucleosis. Reproduced, with permission, from Smith. ${ }^{17}$ Churchill-Livingstone $\bigodot^{\text {, Elsevier. }}$ 
Table 1 Patients and controls

\begin{tabular}{|c|c|c|c|c|}
\hline & \multicolumn{3}{|l|}{ Patients } & \multirow[b]{2}{*}{ Controls } \\
\hline & Fatal & Septic shock survived & No shock & \\
\hline $\mathrm{n}$ & 14 & 26 & 48 & 50 \\
\hline \multicolumn{5}{|l|}{ Age } \\
\hline Mean* (SD) & 12.9 (16.3 years) & 21.3 (18.7 years) & 21.8 (22.9 years) & 27.6 (25.9 years) \\
\hline Range & 5 months -58 years & 1 month-59 years & 2 months -92 years & 4 months -46 years \\
\hline Median* (IQR) & 4.5 (1-21 years) & 18.5 years ( $5-21$ years) & 18.0 years $(3.5-25)$ & 9.0 years ( $1.5-15$ years) \\
\hline \multicolumn{5}{|l|}{ Serogroupt } \\
\hline B & $3 / 10(30 \%)$ & $9 / 20(45 \%)$ & $30 / 44(68 \%)$ & \\
\hline C & $7 / 10(70 \%)$ & $9 / 20(45 \%)$ & $12 / 44(27 \%)$ & \\
\hline
\end{tabular}

*No significant difference in means for the patient groups.

tDifference in frequency of serogroup across the three patient categories, $p<0.05$. IQR; interquartile range.

neutropenia and cocci-containing neutrophils. Crucially, apoptotic neutrophils did not contain cocci, and cocci-containing neutrophils were not apoptotic (figure 4). Of the traditional indicators of viral infection, lymphocytopenia was more sensitive than reactive lymphocyte increase or neutropenia, occurring in $77 \%-79 \%$ across all patient groups and in $10 \%$ of controls.

\section{DISCUSSION}

The correlation between magnitude of neutrophil apoptosis and severity of IMD (table 2) suggests a cause-effect relationship. We propose that neutrophil death is a facilitator of IMD rather than an effect for these reasons: (1) Cocci-containing neutrophils were not apoptotic (figure 4) and apoptotic neutrophils did not contain cocci; these observations are in accord with studies suggesting that phagocytosed Neisseriea sp. can manipulate intracellular processes to enhance the survival of the neutrophil as a safe haven for dissemination of the infection. ${ }^{27}$ (2) The apoptosis of neutrophils and the death of lymphocytes which accompanies it in viral infection cannot be attributed to the operation of a Panton-Valentine type leucocidin (PVL): the meningococcus is incapable of producing PVL, and PVL targets neutrophils but not lymphocytes. ${ }^{28}$ (3) Neutrophil and lymphocyte apoptosis is a recognised effect of viral infection as noted in the Introduction section.

These observations substantiate the recognised linkage between viral infection and IMD. Of the leucocytic indicators of viral infection, neutropenia is the least specific, resulting as it

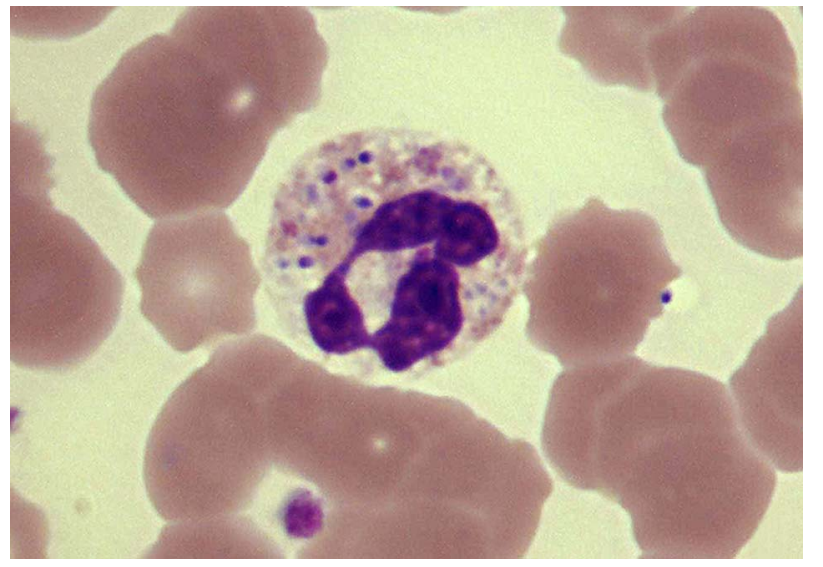

Figure 4 Neisseria meningitidis within neutrophil, which is well preserved, blood film, invasive meningococcal disease. Courtesy of RG Wells. may, from viraemia and from the disseminated intravascular coagulation which is common in severe IMD. ${ }^{29}$ In the discussion following therefore, we assume without prejudice, that apoptosis is cause rather than effect and that apoptosis is a result of viral infection and not of meningococcaemia.

The lymphocyte apoptosis which accompanies neutrophil apoptosis may be significant in pathogenesis of IMD by disrupting the T-B lymphocyte activation and interaction required for generation of bactericidal antibody. ${ }^{67}$ We have obtained preliminary confirmation of virus-associated lymphocyte apoptosis using flow cytometric assessment of annexin-V binding ${ }^{30}$ in IM, which showed enhanced binding by CD4, CD19, and especially $\mathrm{CD} 8$, but not natural killer lymphocytes (Smith $\mathrm{H}$, unpublished). Apoptosis of monocytes, which may accompany the death of neutrophils and lymphocytes in viral infection, ${ }^{16}$ may contribute to pathogenesis of IMD by impairing the clearance of cocci and cocci-containing neutrophils.

Virus-associated apoptosis of neutrophils is not for the most part a consequence of viral penetrance of the cells. For example, in vitro studies of neutrophil apoptosis induced by herpes simplex virus (HSV)- $1^{31}$ and influenza virus-A (IVA) ${ }^{32}$ showed that the majority of apoptotic cells were not infected; in IM, only a small minority of blood neutrophils contain Epstein-Barr virus (EBV), ${ }^{33}$ though in vitro, a substantial proportion of neutrophils can bind EBV in spite of their lack of the EBV receptor, CD21. ${ }^{34}$ Virus-induced neutrophil apoptosis is attributed to upregulation of Fas and Fas-L on the few cells that are infected, with release of soluble Fas- $\mathrm{L}$ to then diffuse and bind to Fas-receptor on uninfected cells to initiate apoptosis. ${ }^{35}$ It is also possible that the susceptibility of neutrophils in vitro to the destructive effect of tumour necrosis factor (TNF)- $\alpha^{35}$ renders them vulnerable in vivo as well to TNF- $\alpha$ released from apoptotic lymphocytes whose death accompanies neutrophil death in viral infection. Neonatal, in contrast to adult neutrophils, may be especially susceptible to viral destruction, at least by HSV-1 ${ }^{31}$ which correlates with the marked leucocyte death in neonatal herpes simplex viraemia (figure 1 ). ${ }^{20}$

As with apoptosis of neutrophils, virus-induced death of lymphocytes is in general associated with low viral penetrance into cells and heightened Fas (CD95) expression. The in vitro induction of lymphocyte apoptosis by IVA ${ }^{36}$ affects CD8 rather than CD4 lymphocytes, and is diminished by anti-Fas but not anti-TNF- $\alpha$ antibodies; the clinical virulence of IVA strains correlated with the capacity to induce lymphocyte apoptosis and with neuraminidase activity. In IM, the expanded CD8 population shows strong expression of markers of activation ${ }^{24} 25$ and $\mathrm{Fas}^{22}$ and high susceptibility to apoptosis in culture, ${ }^{23} 25$ and in 
Table 2 Leucocyte data, patients and controls

\begin{tabular}{|c|c|c|c|c|c|}
\hline & \multicolumn{4}{|l|}{ Patients } & \multirow[b]{2}{*}{ Controls } \\
\hline & Fatal & Septic shock survived & No shock & Difference between patient groups & \\
\hline \multicolumn{6}{|l|}{ Dead leucocytes any type } \\
\hline Subjects & 13/14 (93\%) & $16 / 26(62 \%)$ & 18/48 (38\%) & & $0 / 50$ \\
\hline Per $\mathrm{mm}^{3}$, mean $(\mathrm{SD})$ & $89.3(78.6)$ & $46.6(80.3)$ & $34.9(117.6)$ & $p<0.0003$ & \\
\hline \multicolumn{6}{|l|}{ Dead neutrophils } \\
\hline Subjects & $9 / 14(64 \%)$ & $13 / 26(50 \%)$ & $16 / 48(33 \%)$ & & 0 \\
\hline Per $\mathrm{mm}^{3}$, mean (SD) & $36.5(47.8)$ & $19.5(28.3)$ & $9.6(16.5)$ & $p=0.03$ & \\
\hline \multicolumn{6}{|l|}{ Neutropenia* } \\
\hline Subjects & $5 / 14(36 \%)$ & $2 / 26(8 \%)$ & $1 / 48(2 \%)$ & $p<0.0001$ & $1 / 50(2 \%)$ \\
\hline \multicolumn{6}{|l|}{ Neutrophils with cocci } \\
\hline Subjects & $11 / 14(79 \%)$ & $4 / 26(15 \%)$ & $1 / 48(2 \%)$ & & 0 \\
\hline Per $\mathrm{mm}^{3}$, mean (SD) & $48.6(43.4)$ & $4.9(13.0)$ & $0.4(2.7)$ & $\mathrm{p}<0.0001$ & \\
\hline \multicolumn{6}{|l|}{ Dead lymphocytes } \\
\hline Subjects & $13 / 14(93 \%)$ & $12 / 26(46 \%)$ & $10 / 48(21 \%)$ & & $0 / 50$ \\
\hline Per $\mathrm{mm}^{3}$, mean (SD) & $42.0(52.7)$ & $17.1(26.9)$ & $22.0+(107.4)$ & $\mathrm{p}<0.0001$ & \\
\hline \multicolumn{6}{|l|}{ Lymphocytopenia } \\
\hline Subjects & $11 / 14(79 \%)$ & $20 / 26(77 \%)$ & $38 / 48(79 \%)$ & $\mathrm{p}=0.98$ & $5 / 50 \ddagger(10 \%)$ \\
\hline \multicolumn{6}{|c|}{ Reactive lymphocyte increase } \\
\hline Subjects & $5 / 14(36 \%)$ & $9 / 26$ (35\%) & $9 / 48(19 \%)$ & $p=0.18$ & $4 / 50 \S(8 \%)$ \\
\hline
\end{tabular}

vivo (Smith $\mathrm{H}$, unpublished). Although EBV can infect CD4 and CD8 T lymphocytes in vitro, ${ }^{37}$ the expanded EBV-specific CD8 population in IM is not infected $;^{23}$ and though Fas is upregulated on this population, inhibition studies show that the Fas system is not required for their apoptosis in culture ${ }^{25}$ (compare with IVA above). The cellular toxicity of cytochrome-c if released from damaged mitochondria, together with the fact that IM T cells in culture can be rescued from apoptosis by a range of cytokines, has suggested a mitochondrial/cytokine rescuable mechanism for the cell death. ${ }^{25}$ Interleukin-2, as an inhibitor of apoptosis, ${ }^{38}$ may have especial relevance, being markedly depleted in apoptosis-prone IM T cells in culture. ${ }^{39}$ In neonatal herpes simplex viraemia, the virus can invade and destroy lymphocytes. ${ }^{20}$

The relation between clinical severity and burden of coccicontaining neutrophils (table 2) accords with the experience that the main determinant of clinical severity in IMD is the magnitude of the bacteraemia. ${ }^{29}$

In the wider context of virus-induced pathology, we suggest that leucocyte apoptosis is a likely contributor to a range of viral effects: (a) Leucocyte death would add to T lymphocyte activation and proliferation as a source for the increase in plasma cytokines to which the malaise and fever of viral infection are attributed. ${ }^{40}$ A linkage between a profusion of apoptotic lymphocytes in the blood film in IM and a more severe and protracted illness ${ }^{19}$ supports this proposition. (b) Shedding from degenerating leucocytes would be a source of phosphatidylserine, which has the capacity to complex with plasma coagulation factors such as prothrombin, to enhance their antigenicity and generate antiphospholipid antibodies (lupus type anticoagulants) ${ }^{41}$ which are a not uncommon, transient occurrence in viral infections. ${ }^{42}$ (c) Leucocyte apoptosis may contribute to the neutropenia and lymphocytopenia of viral infection. (d) Leucocyte apoptosis may add to the increase in serum lactate dehydrogenase resulting from the liver damage and, less commonly, the immune haemolysis of viral infection. ${ }^{15}$ (e) Apoptosis contributes to depletion of CD4 lymphocytes which, together with depletion of functional macrophages, underlies the cutaneous anergy, as assessed by delayed hypersensitivity testing, which is common and severe in measles, ${ }^{43} 44$ and less so in IM. $^{45}$ (f) The high increase in serum levels of soluble (s) CD8 in IM (sCD8 102× normal, sCD $4 \sim 1.2 \times$ normal $^{46}$ may be attributed to high activation and proliferation of the CD8 population, and to its high death rate in vivo (see above). (g) Leucocyte apoptosis, by stimulating phagocytosis, and activation of macrophages may be significant in the genesis of virus-associated haemophagocytic syndrome, ${ }^{47}$ the morphology of which can be readily appreciated in first drop earlobe blood films (figure 3), a technique now rarely employed. ${ }^{16}$

The model we propose for virus-IMD association may also apply to other viral-bacterial associations, such as postinfluenzal pneumococcal sepsis, and neonatal herpes simplex viraemia presenting as bacterial septicaemia.

\section{What the study adds}

Haematological indicators of viral infection substantiate the association of viral infection with invasive meningococcal disease (IMD). Leucocyte apoptosis is a morphological expression of viral immunosuppression and a likely facilitator of IMD: neutrophil death by impairing phagocytic capacity, and lymphocyte death by impairing generation of microbicidal antibody. In the wider context of viral pathology, we suggest that leucocyte apoptosis is a likely contributor to a range of viral effects, including fever and malaise, lupus-type anticoagulants, blood cytopenias, cutaneous anergy, and virus-associated haemophagocytic syndrome. 


\section{Take home messages}

- Haematological indicators of viral infection substantiate the association of viral infection with invasive meningococcal disease (IMD).

- Leucocyte apoptosis is a morphological expression of viral immunosuppression and a likely facilitator of IMD by impairing two arms of the immune system: phagocytic capacity (neutrophil death) and generation of microbicidal antibody (lymphocyte death).

- Leucocyte apoptosis is a likely contributor to a range of viral effects.

- The virus-meningococcal link may be a model for other viral-bacterial associations.

- We suggest that virus-associated leucocyte apoptosis merits more detailed analysis.

Acknowledgements We thank the following for their assistance in this study: $M$ Coulthard, L Dial, J Faoagali, S Hall, Herston Medical Library, S Miller, R Minchinton, J McEniery, R Potter, R Prentice, C Wainwright and B Webster.

Contributors HS: conception, design and coordination; writing of manuscript, which was approved by all coauthors. SLR: blood film microscopy. HVS: meningococcus identification and serogrouping. DG: critical commentary on immunological aspects of the phenomenon. VS: statistical analysis. JAS: sourcing and critical assessment of references, presentation of manuscript.

Funding Royal Brisbane and Women's Hospital Foundation.

Competing interests None.

Ethics approval Only blood samples already taken for routine diagnostic purposes were used in this study. Queensland Health Research Ethics Committee approval HREC/03/QH/029, Chair Professor M Eadie

Provenance and peer review Not commissioned; externally peer reviewed.

Open Access This is an Open Access article distributed in accordance with the Creative Commons Attribution Non Commercial (CC BY-NC 3.0) license, which permits others to distribute, remix, adapt, build upon this work non-commercially, and license their derivative works on different terms, provided the original work is properly cited and the use is non-commercial. See: http://creativecommons.org/ licenses/by-nc/3.0/

\section{REFERENCES}

1 Cartwright $\mathrm{K}$, Jones $\mathrm{D}$, Smith $\mathrm{A}$, et al. Influenza A and meningococcal disease. Lancet 1991;338:554-7.

2 Moore P, Hierholzer J, DeWitt W, et al. Respiratory viruses and mycoplasma as cofactors for epidemic group A meningococcal meningitis. JAMA 1990;264:1271-5.

3 Robinson P, Taylor K, Nolan T. Risk-factors for meningococcal disease in Victoria, Australia in 1997. Epidemiol Infect 2001:127:261-8.

4 McCall B, Neill A, Young M. Risk factors for invasive meningococcal disease in southern Queensland 2000-2001. Internal Med J 2004;34:464-68.

5 Coen P, Tully J, Stuart J, et al. Is it exposure to cigarette smoke or to smokers which increases the risk of meningococcal disease in teenagers? Int J Epidemiol 2006;35:330-6.

6 Robinson K, Neal K, Howard C, et al. Characterization of humoral and cellular immune responses elicited by meningococcal carriage. Infect Immun 2002;70:1301-9.

7 Foster R, Carlring J, Lees A, et al. Functional T-cell deficiency in adolescents who experience serogroup $C$ meningococcal disease despite receiving the meningococcal serogroup C conjugate vaccine. Clin Vacc Immunol 2010;17:1104-10.

8 Hibberd M, Sumiya M, Summerfield J, et al., and the Meningococcal Research Group. Association of variants of the gene for mannose-binding lectin with susceptibility to meningococcal disease. Lancet 1999;353:1049-53.

9 Eisen D, Minchinton R. Impact of mannose-binding lectin on susceptibility to infectious diseases. Clin Infect Dis 2003;37:1496-505.

10 Sjöholm A, Jönsson G, Braconier J, et al. Complement deficiency and disease: an update. Mol Immunol 2005;43:78-85.

11 Raza M, Ogilvie M, Blackwell C, et al. Effect of respiratory syncytial virus infection on binding of Neisseria meningitidis and Haemophilus influenzae type b to a human epithelial cell line (HEp-2). Epidemiol Infect 1993:110:339-47.
12 De Vrankkriiker A, Wolfs $\mathrm{T}$, Ciofu 0 , et al. Respiratory syncytial virus infection facilitates acute colonization of Pseudomonas aeruginosa in mice. J Med Virol 2009:81:2096-103.

13 Rameix-Welti M, Zarantonelli M, Giorgini $D$, et al. Influenza-A virus neuraminidase enhances meningococcal adhesion to epithelial cells through interaction with sialic acid-containing meningococcal capsules. Infect Immun 2009;77:3588-95.

14 Deghmane A-E, Veckerlé C, Giorgini D, et al. Differential modulation of TNF- $\alpha$-induced apoptosis by Neisseria meningitidis. Plos Pathog 2009; 5:e1000405.

15 Bain B. Blood cells. A practical guide. Oxford: Blackwell Publishing, 2006:204, pp. 400-06.

16 Smith H. A morphological study of histiocytes and phagocytic mononuclear cells in human peripheral blood. MD thesis, Univ of Melbourne, 1966.

17 Smith H. Diagnosis in paediatric haematology. Edinburgh: Churchill Livingstone, 1996:8, pp. 239-71.

18 Fischer M, Guerra C, Hickman J, et al. Peripheral blood lymphocyte apoptosis. A clue to the diagnosis of acute infectious mononucleosis. Arch Pathol Lab Med 1996;120:951-5.

19 Lach-Szyrma V, Brito-Babapulle F. The clinical significance of apoptotic cells in peripheral blood smears. Clin Lab Hematol 1999;21:277-80.

20 Smith H. Leucocyte death in generalized virus infection. The Australian Paed J 1969;5:56-61.

21 Smith $\mathrm{H}$. The prevalence and diagnostic significance of "histiocytes" and phagocytic mononuclear cells in peripheral blood films. Med J Aust 1964;2:205-10.

22 Sato T, Hirasawa A, Kawabuchi Y, et al. Cellular expressions and serum concentrations of Fas ligand and Fas receptor in patients with infectious mononucleosis. Int J Hematol 2000;72:329-36.

23 Moss D, Bishop C, Burrows S, et al. T lymphocytes in infectious mononucleosis. I. T cell death in vitro. Clin Exp Immunol 1985;60:61-9.

24 Uehara T, Miyawaki T, Ohta K, et al. Apoptotic cell death of primed CD45RO+ T lymphocytes in Epstein Barr virus-induced infectious mononucleosis. Blood 1992:80:452-58.

25 Callan M, Fazou C, Yang H, et al. CD8+ T-cell selection, function, and death in the primary immune response in vivo. J Clin Invest 2000;106:1251-6.

26 Dacie JV, Lewis SM. Practical haematology. 7th edn. London: Churchill Livingstone, 1991:4.

27 Criss A, Siefert H. A bacterial siren song: intimate interactions between Neisseria and neutrophils. Nature Rev 2012;10:178-90.

28 Genestier A-L, Michallet M-C, Prévost G, et al. Staphylococcus aureus Panton-Valentine leucocidin directly targets mitochondria and induces Bax-independent apoptosis of human neutrophils. J Clin Invest 2005;115:3117-27.

29 Van Deuren M, Brandtzaeg P, van der Meer J. Update on meningococcal disease with emphasis on pathogenesis and clinical management. Clin Microbiol Rev 2000;13:144-66.

30 Van Engeland M, Nieland L, Ramaekers F, et al. Annexin V-affinity assay: a review on an apoptosis detection system based on phosphatidylserine exposure. Cytometry 1998;31:1-9.

31 Ennaciri J, Menezes J, Proulx F, et al. Induction of apoptosis by Herpes Simplex virus-1 in neonatal, but not adult, neutrophils. Pediatr Res 2006:59:7-12.

32 Colamussi $M$, White $M$, Crouch $E$, et al. Influenza A virus accelerates neutrophil apoptosis and markedly potentiates apoptotic effects of bacteria. Blood 1999;93:2395-403.

33 Larochelle B, Flamand L, Gourde $\mathrm{P}$, et al. Epstein-Barr virus infects and induces apoptosis in human neutrophils. Blood 1998;92:291-99.

34 Savard M, Gosselin J. Epstein-Barr virus immunosuppression of innate immunity mediated by phagocytes. Virus Res 2006;119:134-45.

35 Luo H, Loison F. Constitutive neutrophil apoptosis: mechanisms and regulation. Am J Hematol 2008:83:288-95.

36 Nichols J, Niles J, Roberts N. Human lymphocyte apoptosis after exposure to influenza-A virus. J Virol 2001;73:5921-29.

37 Guan M, Romano G, Henderson E. In situ RT-PCR detection of Epstein-Barr Virus immediate-early transcripts in CD4+ and CD8+ T lymphocytes. Anticancer Res 1998; 18:3171-80.

38 Bishop C, Moss D, Ryan J, et al. T lymphocytes in infectious mononucleosis. II. Response in vitro to interleukin-2 and establishment of T-cell lines. Clin Exp Immunol 1985;60:70-7.

39 Attarbaschi T, Willheim M, Ramharter $M$, et al. T cell cytokine profile during primary Epstein-Barr virus infection (infectious mononucleosis). Eur Cytokine Netw 2003:14:34-9.

40 Corsi M, Ruscica M, Passoni D, et al. High TH1-tpye cytokine serum levels in patients with infectious mononucleosis. Acta Virol 2004:48:263-66.

41 Mizumoto H, Maihara T, Hiejima E, et al. Transient antiphospholipid antibodies associated with acute infections in children: a report of three cases and a review of the literature. Eur J Pediatr 2006;165:484-88.

42 Shiomou K, Galanakis E, Tzoufi M, et al. Transient lupus anticoagulant and prolonged activated partial thromboplastin time secondary to Epstein-Barr virus infection. Scand J Infect Dis 2002:34:67-9. 
43 Tamashiro V, Perez H, Griffin D. Prospective study of the magnitude and duration of changes in tuberculin reactivity during uncomplicated and complicated measles. Paediatr Infect Dis J 1987:6:451-4.

44 Okada H, Kobune F, Sato TA, et al. Extensive lymphopenia due to apoptosis of uninfected lymphocytes in acute measles patients. Arch Virol 2000;145:905-20.
45 Haider S, de Coutinho M, Edmon R. Tuberculin anergy and infectious mononucleosis. Lancet 1973;2:74.

46 Yoneyama A, Nakahara K, Higashihara M, et al. Increased levels of soluble CD8 and CD4 in patients with infectious mononucleosis. Br J Haematol 1995;89:47-54.

47 Maakaroun NR, Moanna A, Jacob JJ, et al. Viral infections associated with haemophagocytic syndrome. Rev Med Virol 2010;20:93-105. 